\title{
The Matrix and Parameters of the "Jiugong-Modes" of the Chinese Basic Intonation
}

\begin{abstract}
Wu Jiemin *
Abstract: The author outlines the matrix and parameters of the forms of basic intonation of Chinese texts, and, based on the traditional Chinese graphic expression Jiugong(nine squares), systematically describes the tonal ranges and various forms of basic intonation. She concludes that if we express the pitch and length of the texts by means of two coordinate axes, and each coordinate axis is divided into three levels, a Jiugong matrix of intonation will be established, and different two-dimensional acoustic features can be found at various points on the Jiugong diagram. The Jiugong matrix of intonation as expounded in this paper serves as the rules for the combination of intonations and covers all the basic tones of Chinese texts.
\end{abstract}

Key words: intonation, Jiugong-modes, matrix, parameters

\section{Introduction}

Suprasegmental features are the necessary components in speech. The basic intonations are the suprasegmental features on the discourse level, namely the main tone of the discourse. It includes intonation patterns and intonation modes. The intonation patterns are types of intonation, which are mainly caused by the changes of the pitch in the sentence. There are five intonation patterns in Chinese: flat, falling, rising, rise-fall and fall-rise. When the tone patterns differ, the meanings differ correspondingly. Take the sentence “tāmen shì xuéshēng (他们是学生)" for an example. It is a rhetorical question if said in the rising tone, and means, "They are NOT students." It is a confirmation in the falling tone, meaning "They ARE students." It is rebut in the rise-fall tone, meaning, "They are students, not teachers."

The intonation modes refer to the modes of the pitch and length changes in the discourses. There are two aspects in the intonation modes. One is the pitch level, which is mainly formed by the pitch changes out of the discourse. The meanings differ when the pitch levels are different.

(1)C. $\uparrow$ Wǒ shuō le. (我说了。)

\footnotetext{
* Wu Jiemin: School of Foreign Languages, Zhejiang University, No.34 Tianmushan Road, Hangzhou 310028, Zhejiang, China. E-mail: wujmn@mail.hz.zj.cn.
} 
High pitch level, when one is going to disclose a secret or report a piece of good news. B. $\rightarrow$ Wǒ shuōle. (我说了。)

Medium pitch level, when narrating something peacefully.

A. $\downarrow$ Wǒ shuōle. (我说了。)

Low pitch level, when blaming oneself for saying something that should not have been said.

The other is the tempo of speech, which is formed by the change of the foot length. Even when one is calling someone's name, it will have different meaning if said in different tempo. For example:

(2)a. Zhāng Xiăopíng. (张小萍。)

In high tempo, low pitch level, may be in class when the teacher is reminding her to be attentive.

b. Zhāng Xiăopíng. (张小萍。)

In medium tempo and medium pitch level, may be in class when the teacher is asking her to answer questions.

c. Zhāng ...Xiăo...píng... (张小萍。)

Calling loudly in low tempo, may be on the occasion when looking for her in the wildness.

It can be found that both the pitch level and the tempo are expressively functional. The paper mainly probes into the rules of intonation modes in the Chinese basic intonations (namely the matrix of the Jiugong modes of the Chinese basic intonations), and the methods of determining the range of the basic intonations.

\section{The two-dimension hierarchy of the Chinese basic intonations and the definition of range}

The British phonetician D.Jones (1881-1967) exactly and systematically described vowels with his quadrilateral figure of the vowels. Inspired by his figure, a quadripolar figure of the range of basic intonations of the discourses is presented here for the first time, in order to describe the two-dimension range and the system of the intonation modes.

When the speakers express different meanings in different situations, the suprasegmental features in the speech are different, but each has its own basic intonation and two parameters can be found from the variants of the pitch and length. We divide a person's pitch in the basic intonation into such three levels as low (A), medium (B), and high (C), and the tempo into such three rates as fast (a), medium (b) and slow (c). Assuming $+\mathrm{C}$ and $+\mathrm{A}$ are the two poles from the high pitch level to the low one, and assuming $+\mathrm{a}$ and $+\mathrm{c}$ are the two poles from the fast rate to the slow rate, we can define the four poles of the tone range as follows:

$+\mathrm{Aa}$ is the lowest and fastest pole in the range; 
$+\mathrm{Ac}$ is the lowest and slowest pole in the range;

$+\mathrm{Ca}$ is the highest and fastest pole in the range;

$+\mathrm{Cc}$ is the highest and slowest pole in the range.

A format of tone range can be obtained by joining the four poles (shown in Figure 1.):

Figure 1: The four poles of the range of basic intonations

\begin{tabular}{ll|}
$+\mathrm{Ca}$ & $+\mathrm{Cc}$ \\
$+\mathrm{Aa}$ & $+\mathrm{Ac}$ \\
\hline
\end{tabular}

\section{The matrix of the Jiugong intonation modes of the Chinese basic intonations}

Take the pitch and the tempo (rate) as the vertical coordinate axis and the horizontal axis respectively and divide the pitch into three levels A, B and C from the low to the high, and divide tempo into $\mathrm{a}, \mathrm{b}$ and $\mathrm{c}$ from fast to slow, then the structural hierarchy will be as shown in Figure 2.

If the three pitch levels and the three tempos are linked by dotted lines, the matrix of the Jiugong intonation modes of the Chinese basic intonations is formed, and there will be such intonation modes in the sketch of the range as shown in Figure 3: $\mathrm{Aa}, \mathrm{Ab}, \mathrm{Ac} ; \mathrm{Ba}, \mathrm{Bb}, \mathrm{Bc}$; $\mathrm{Ca}, \mathrm{Cb}, \mathrm{Cc}$. Among them, $\mathrm{Cb}, \mathrm{Ba}, \mathrm{Ab}, \mathrm{Bc}$ are neutral intonation modes; the medium tempo and medium pitch level $\mathrm{Bb}$ is the pattern of harmony, while $\mathrm{Ca}, \mathrm{Cc}, \mathrm{Aa}, \mathrm{Ac}$ are the four terminal patterns. The matrix is as follows:

Figure 2: Pitch and length as the two coordinate axes of the range

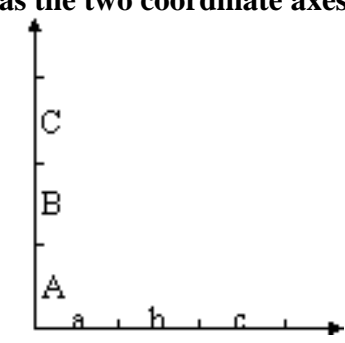

Figure3:The matrix of the "Jiugong-modes" of the Chinese Basic Intonation

\begin{tabular}{|c:c:c|}
\hline $\begin{array}{c}\text { High-fast } \\
\mathrm{Ca}\end{array}$ & $\begin{array}{c}\text { High-medium } \\
\mathrm{Cb}\end{array}$ & $\begin{array}{c}\text { High-slow } \\
\mathrm{Cc}\end{array}$ \\
\hline $\begin{array}{c}\text { Medium-fast } \\
\mathrm{Ba}\end{array}$ & $\begin{array}{c}\text { Medium-medium } \\
\mathrm{Bb}\end{array}$ & $\begin{array}{c}\text { Medium-slow } \\
\mathrm{Bc}\end{array}$ \\
\hdashline $\begin{array}{c}\text { Low-fast } \\
\mathrm{Aa}\end{array}$ & $\begin{array}{c}\text { Low-medium } \\
\mathrm{Ab}\end{array}$ & $\begin{array}{c}\text { Low-slow } \\
\mathrm{Ac}\end{array}$ \\
\hline
\end{tabular}

The Jiugong intonation mode can not be simply rendered into "nine modes". It stands for the combination rules in the matrix of basic intonations in the Chinese language. "Jiu" 
(which means nine if translated word for word) is used to represent plentitude, as in the traditional Chinese culture where it was a digit meaning the most, as well as nine in the most general case. We use the Jiugong ${ }^{\mathbb{1}}$ figure to describe the combination modes of the Chinese basic intonations and thereafter determine the matrix. The variations of loudness, length and tempo in the speech flow, or the conservation and variation of speech, or the opposition and unification of speech, can all be explained by the matrix. Some combination rules of the basic intonations can thereafter be revealed.

\section{Acoustic parameters of the Jiugong intonation modes}

There are all kinds of suprasegmental features in the flow of speech. The main elements that make the basic intonations include pitch, length and stress. Unlike English, Chinese is a tonal language. The strength of the syllables is modulated by word tones, thus losing its status as a distinctive feature. The sentential stress is expressed by increasing the length and enlarging the range of intonation. Here we mainly explore the differential parameters of pitch and length in the Jiugong intonation modes and do not take the features of loudness into consideration at this time.

\subsection{Pitch level parameters}

According to the phonetic experiments, the female sound pitch parameters of the three pitch levels are presented in Table 1.

Table 1. Sound parameters of the pitch levels

\begin{tabular}{|c|c|c|}
\hline pitch level & $\begin{array}{c}\text { the upper and lower limit parameters } \\
\text { of the basic intonations }\end{array}$ & range \\
\hline High pitch level (C) & $450-270 \mathrm{~Hz}$ & $180 \mathrm{~Hz}$ \\
\hline Medium pitch level (B) & $330---150 \mathrm{~Hz}$ & $180 \mathrm{~Hz}$ \\
\hline Low pitch level (A) & $250---110 \mathrm{~Hz}$ & $140 \mathrm{~Hz}$ \\
\hline
\end{tabular}

When a speaker utters his first foot of sound, he determines his pitch level of the Basic intonations. It is just like the first note you sing decides your music tone. Once the pitch level is determined, it is very hard for one to break through the upper limit. The breakthrough will force the pitch level to be moved to a higher one. The breakthrough of the upper limit of the high pitch level will lead to falsetto, while the breakthrough of the lower limit is quite common, unless when it is already impossible to lower it as the lower pitch hits the lowest limit of the speaker. Unlike that of the high or medium pitch level, the low limit of the low pitch level can not be lowered any more, as the low limit of the range will be broken through and the speech will be impossible. Even if there can be utterances, they

\footnotetext{
(1) “Jiugong” is a concept of the Yi (《易》) in ancient China. It was used to explain the universe in Yi Wei (《易纬》). Jiugong was also applied in the calendar, meteorology, mathematics, military and so on in the history of China.
} 
are not distinctive. Usually the fundamental frequency is invisible in the spectrogram, and the reception of information is affected. The different pitch levels affect the tones in speech chains and the tone value is subject to change.

\subsection{Tempo parameters}

According to the listening test of speech materials in different styles for different subjects, we suppose that the acoustic parameters of the fast tempo (c), medium tempo (b), and slow tempo (a) are as follows in Table 2. (The syllable length includes the blanks, and the tempo is counted in seconds.)

Table 2. Tempo parameters

\begin{tabular}{|l|l|}
\hline Fast tempo (a) & $110 \mathrm{~ms}----300 \mathrm{~ms} /$ syllable \\
\hline Medium tempo(b) & $250 \mathrm{~ms}----450 \mathrm{~ms} /$ syllable \\
\hline Slow tempo (c) & $400 \mathrm{~ms}----650 \mathrm{~ms}----1000 \mathrm{~ms} /$ syllable \\
\hline
\end{tabular}

Professor $\mathrm{Wu}$ Zongji measured the tempo of a live broadcast of an international soccer match in 1993 and found that the fastest tempo of Chinese is $110 \mathrm{~ms} / \mathrm{syllable}$. This matches our experiments. The slow tempo in Chinese is usually $450 \mathrm{~ms}----650 \mathrm{~ms} / \mathrm{syllable}$. Language sense tests found that the tempo of $1000 \mathrm{~ms} / \mathrm{syllable}$ is a critical parameter for expressing special feelings. At this tempo (including the pause caused by the blank in the speech stream), what we usually find is the state of being too excited to speak. In some special situations the tempo can be as slow as $1300 \mathrm{~ms} /$ syllable or even $1500 \mathrm{~ms} /$ syllable. The above example (2)c. (calling Zhang Xiaoping in the wilderness) is at this tempo. On such occasions this kind of utterance is only one single sentence, or at most a short fragment, whose tempo will not exceed 1000ms/syllable in the discourse. Furthermore, the tempo of the old is much slower than that of the young, the tempo of a man is slower than that of a woman, and utterance is also usually characterized by idiolectic features. With the speedup of the life pace, the newscast tempo has increased from the average of $330 \mathrm{~ms} / \mathrm{syllable}$ to $240 \mathrm{~ms} / \mathrm{syllable}$, namely from medium tempo to fast tempo. But there is no difference in meaning; only in the amount of information.

The combination of the pitch level parameter and the tempo parameter makes the acoustic parameters of the Jiugong intonation modes. But the three levels of pitch and tempo have large spans and are intersected. The dotted lines in the figure indicate the vague marks between different patterns, so the pattern symbols are marked with \pm .

\section{The expressive function of the Jiugong intonation modes}

Each square in the Jiugong diagram represents the range of the corresponding intonation mode. Every different position in the matrix has different acoustic parameters and expresses different meanings. The meaning expressed can be slightly different when the two 


\section{Wu Jiemin}

dimensional parameters are different, even if the utterances are in the same intonation mode. Even the utterances with the same sequences of Shengmu (the initial consonant), Yunmu (the final of a syllable in Chinese) and tone can be emotionally and semantically different when the acoustic parameters are different.

Based on experimental measurement, we found that the parameters of the intonation mode of the above given example (2) are as follows:

(2)a, pitch level $270-110 \mathrm{~Hz}$, tempo $135 \mathrm{~ms} /$ syllable, intonation mode Aa (low pitch level and fast tempo).

(2)b, pitch level $320-125 \mathrm{~Hz}$, tempo 230ms/syllable, intonation mode $\mathrm{Bb}$ (medium pitch level and medium tempo).

(2)c, pitch level $440-375 \mathrm{~Hz}$, tempo $1500 \mathrm{~ms} /$ syllable, intonation mode $+\mathrm{Cc}$ (high pitch level and fastest tempo). Its tempo is not common.

Testing the above sentences on 40 students of the English department revealed that the recognition of meaning, when the sentences are given without situations or contexts, reaches the rate of $98 \%$. So it is definitely the intonation mode that expresses specific meanings in specific situations. In the live broadcast of a fierce ball game, only in fast tempo and high pitch level can the live situation be broadcasted accurately. For example:

(3) Xià bàn chăng de bǐsài yìjing jìnxíng le 17 fên líng 15 miăo.(下半场的比赛已经进行了 17 分零 15

秒。/ We are in the 17th minute and 15th second of the second half of the game.)

The experiment by Professor Wu Zongji reveals that the pitch level of this sentence is $150-350 \mathrm{~Hz}$, and the tempo 9 syllables per second. The duration of every syllable averages to $111 \mathrm{~ms}$. This is the intonation mode Ca with the highest pitch level and fastest tempo. The Chinese can still recall the live broadcasting of the $26^{\text {th }}$ World Table Tennis Championship in 1961. Song Shixiong commented on the match in the high-pitch fast-tempo intonation mode. He made hundreds of thousands of audience share the glory and the joy.

For another example, when Jiang Qing spoke in public, she usually chose the highest-pitch slowest-tempo pattern. The following is a fragment of her recorded speech at the Beijing Broadcasting Institute on July $24^{\text {th }}, 1966$ :

(4) Gémìng tóngxuómen... $\nearrow$ nǐmen hăo... \wǒ dàibiǎo Máozhǔxí... $\nearrow$ wènhòu

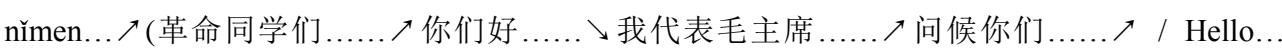

revolutionary comrades... I great you... on behalf of Chairman Mao.)

With her special status Jiang Qing broke through the upper limit of the $+\mathrm{C}$ level pitch and used falsetto in front of the hundreds of thousands of captivated audience. The length reaches the extreme of the +a tempo, and the intonations of most phrases are in the rising tone. At that time only, Jiang Qing could speak in that tone.

If the sentences are uttered in the $+\mathrm{Cc}$ intonation mode, the recognition rate can reach $100 \%$ for those who have heard her recording, as shown in Table 3 . 
The Matrix and Parameters of the "Jiugong-Modes" of the Chinese Basic Intonation

Table 3. The syllable length of the same sentence when used to express different ideas:

\begin{tabular}{|c|c|c|c|c|}
\hline Syllables & Colloquial style & Political essay & Artistic style 1 & Artistic style 2 \\
\hline $\operatorname{tā}($ (他) & 113 & 170 & 123 & 148 \\
\hline shuō(说) & 187 & 490 & 205 & 468 \\
\hline & 0 & 750 & 0 & 1585 \\
\hline rén(人) & 240 & 300 & 262 & 479 \\
\hline shēng(生) & 372 & 310 & 500 & 570 \\
\hline & 0 & 0 & 1000 & 1687 \\
\hline méi(没) & 121 & 250 & 336 & 331 \\
\hline yǒu(有) & 221 & 250 & 622 & 353 \\
\hline & 49 & 120 & 828 & 0 \\
\hline br̀(笔) & 169 & 195 & 221 & 125 \\
\hline & 30 & 40 & 0 & 0 \\
\hline zhí(直) & 199 & 190 & 238 & 182 \\
\hline de(的) & 82 & 85 & 115 & 91 \\
\hline lù(路) & 154 & 210 & 205 & 228 \\
\hline Average length & 194 & 336 & 466 & 625 \\
\hline Intonation modes & $\mathrm{Ba}$ & $\mathrm{Bb}$ & $\mathrm{Bc}$ & Ac \\
\hline
\end{tabular}

There is no difficulty in determining the Intonation modes according to the pitch and length features in talking or reading, the extreme patterns in particular. Their recognition rate can be even higher. We tested the listeners with the following sentence

(5) Tā shuō rénshēng méiyǒu bǐzhíde lù. (他说人生没有笔直的路。/ He said there were no straight roads in life.)

The expressive functions of the different intonation modes are as follows:

(5) Ba. When said in medium pitch level and fast tempo, the sentence is regarded as emotionless by the speaker and suitable for the casual or colloquial style.

(5) $\mathrm{Bb}$. When read in medium pitch and medium tempo, it is regarded as a serious narration of the philosophy of life by the speaker. It is suitable for the colloquial style on formal occasions or in political essays.

(5) Bc. In medium pitch and slow tempo, the stress is on “没有”. This expresses the speaker's own experience. It's suitable for artistic styles.

(5) Ac. In low pitch level and slow tempo, the emphasis on “人生” reveals the speaker's heavy and sentimental mood as one has when narrating sad experiences.

188 college students were tested with this sentence. The recognition rate of the above expressive functions of the different intonation modes reached $94-100 \%$. Of course, there 
are other factors such as the levels of phonetic segmentation (see Figure 4). Though both $\mathrm{Bc}$ and Ac belong to slow tempo, the intonation mode parameter is different, so the ideas and feelings expressed are therefore different. The intonation modes have the function of expressing ideas, feelings and attitudes.

\section{The Jiugong intonation modes can cover all the basic intonations in Chinese}

The Jiugong intonation modes can cover all the Basic intonations in Chinese. When utterances shift from the highest and fastest $+\mathrm{Ca}$ intonation mode to the right of the matrix of the Jiugong intonation modes, there is no change in its high pitch level, but there is a slowdown of the tempo. When it reaches $\mathrm{Cb}$, the utterance has the intonation mode of high-pitch level medium tempo. If the movement to the right continues, the tempo becomes even slower, while the pitch remains unchanged. $+\mathrm{Cc}$ is the extreme intonation mode with the highest pitch level and slowest tempo. Moving downward from $+\mathrm{Cc}$, the pitch level lowers while the tempo keeps the same. $\mathrm{Bc}$ is the mode with the slow tempo and medium pitch level. Still further downward to + Ac, it is the extreme mode with the lowest pitch level and slowest tempo. Left to $+\mathrm{Ac}, \mathrm{Ab}$ is the one with the medium tempo and low pitch level. Further left to $+\mathrm{Aa}$, the mode becomes the one with the lowest pitch level and fastest tempo. Upward from Aa, the pitch level becomes higher while the tempo remains the same. $\mathrm{Ba}$ is the one with the medium pitch level and fast tempo. Further upward, the intonation mode returns to the extreme one with the highest pitch level and fastest tempo. The different acoustic features in the matrix can convey various emotions and meanings.

The Jiugong matrix is the principal classification of the intonation modes. Among them, the mode $\mathrm{Bb}$ at the center is the most common one, called the mode of "Great harmony". That is because its suprasegmental features are relatively stable and there is no great change in its pitch level and tempo. What it expresses is mostly "neutrality". In fact, in the man-machine conversation, $\mathrm{Bb}$ is the most usual intonation mode. The four extreme modes $\mathrm{Aa}, \mathrm{Ac}, \mathrm{Ca}$ and $\mathrm{Cc}$ usually express special emotions and thoughts. The four neutral modes $\mathrm{Ba}, \mathrm{Bc}, \mathrm{Ab}$ and $\mathrm{Cb}$ are the second most common ones. Further exploration into the determination of the parameters needs to be done.

It is clear which intonation modes to use when speaking. It would have been unimaginable for Song Shixiong to speak in Ac intonation mode in a live broadcasting. The speaker would no longer be Jiang Qing if the same words were said in $\mathrm{Ba}$ or Ab intonation mode. The features of the basic intonations are in accordance with the speaker's feelings. That is why all kinds of information can be conveyed in different intonation modes. As there is a great variety of human feelings, the features of the intonation mode are therefore likewise changeable. Within the Range of all the intonation modes, any difference of the 
acoustic parameters indicates the difference of meanings and feelings. Therefore, the Jiugong intonation modes can cover all discourse Basic intonations in Chinese.

\section{Conclusion}

The Jiugong matrix outlines the rule of the modes of Chinese Basic intonations. Divide the discourse pitch and the sound length respectively into three levels of low (A), medium (B), high (C), and three tempos of slow (c), medium (b) and fast (a) (3 times 3), then take pitch and length as the two coordinate axes (2 dimensions). By doing so we have the 9 intonation modes in Figure 3 (Jiugong). This is what we call the system of three-three, two-dimensional Jiugong intonation patterns of the Chinese Basic intonations. The matrix and the parameters provide speech systematic engineering with theoretical support for phonetics, and they are of great application value for computer science, information science, neurology, psychology, acoustics, medicine and language teaching.

In addition, each and every one of the nine intonation modes has 5 tones (rising, falling, flat, rise-fall and fall-rise). Actually, we have more than the patterns mentioned above, if one considers such prosodic features as the pitch, speed, length in and out of the sentences together with the tones. The Chinese Basic intonations should be a system of "three-three, two dimension, Jiugong, five-tone " intonation modes.

Speech is a two-way communication of encoding and decoding. The pitch, the length and the tempo in the discourse tones can all convey information. If the Basic intonations are incorrectly used in speaking or reading, the meaning can not be conveyed successfully. The listeners decode the encoded information of the speakers according to the different intonation modes. The common conceptions of the intonation modes by both the speakers and the listeners become the conventionalized speech symbols, and therefore form the premises of human communication.

\section{References}

Chao Yuenren. 1992. Chinese Tones and Intonations (Selected Essays on Linguistics by Y.R.Chao) . [C] Beijing: Tsinghua University Press.

Gui Cankun. 1985. Applied Phonetics of American English. [M] Shanghai: Shanghai Foreign Languages Education Press.

Guo Jinfu. 1993. Illustration and Exploration of the Chinese Tones and Intonations. [M] Beijing: The Press of Beijing Institute of languages.

Jones, D. 1962. An outline of English Phonetics. $9^{\text {th }}$ edition. [M] Cambridge: Cambridge University Press. Luo Changpei, Wang Jun. 1981. An Outline of General Phonetics. [M] Beijing: The Commercial Press.

Wu Jiemin, Lü Shinan. 1997. The Inner and Outer Three Levels of the Extension and Pause in Chinese. [J] Yuwen Xiandaihua ( Modernization of Language and Writting System ). No.3.

Wu Jiemin. 1998. The Rules of the Combination of Intonation Groups in Chinese. [J] Journal of Zhejiang Social Science, No.1.

Wu Zongji. 1996. A New Method of Intonation Analysis for Standard Chinese: Frequency Transposition Processing of Phrase Contours in A Sentence. [A] In G. Fant et.al.(Editors): Analysis, Perception and processing of Spoken Language. [C] Amsterdam: Elsevier. 